\title{
Heidelberg Coping Scales for Delusions: Psychometric Evaluation of an Expert Rating Instrument
}

\author{
Sarah Rückl ${ }^{a}$ Liesa Büche ${ }^{a}$ Nana Christina Gentner ${ }^{a} \quad$ Judith Heyne $^{a}$ \\ Anique von Bock ${ }^{\mathrm{a}}$ Andreas Barthel ${ }^{\mathrm{b}}$ Helmut Vedder ${ }^{\mathrm{b}}$ Martin Bürgy ${ }^{\mathrm{c}}$ \\ Klaus-Thomas Kronmüller ${ }^{\text {a, }}$ \\ ${ }^{a}$ Department of Psychiatry, University of Heidelberg, Heidelberg, ${ }^{b}$ Psychiatric Center Nordbaden, Wiesloch, \\ ${ }^{c}$ Center of Mental Health, Bürgerhospital, Stuttgart, and d Department of Psychiatry, Psychosomatic Medicine and \\ Psychotherapy, LWL-Clinic Gütersloh, Gütersloh, Germany
}

\section{Key Words}

Adaptation - Factor analysis - Psychotic disorders ·

Reliability $\cdot$ Schizophrenia $\cdot$ Validity

\begin{abstract}
Background: Coping is of substantial relevance in the treatment and course of psychiatric disorders. Standardized instruments to assess coping with psychotic symptoms, particularly delusions, are rare. The aim of this study was to develop and evaluate the psychometric properties of a new instrument to assess coping strategies in the context of delusional experiences: the Heidelberg Coping Scales for Delusions (HCSD). Methods: Two hundred and twelve inpatients with schizophrenia spectrum disorders and affective disorders currently experiencing delusions were interviewed with the HCSD and other coping assessment instruments. Psychometric properties and factor structure were analyzed. Results: The HCSD showed good inter-rater reliability and convergent validity. Factor analysis yielded an interpretable structure with five factors: resource-oriented coping, medical care, distraction, cognitive coping, and depressive coping. Symptomatic behavior, due to its particular characteristics, was considered apart. Conclusion: The HCSD is a reli-
\end{abstract}

able and valid instrument for the assessment of coping strategies in patients with delusions. Further research is needed to evaluate coping changes over time and their influence on treatment and clinical outcomes.

Copyright $\odot 2012$ S. Karger AG, Basel

\section{Introduction}

Delusions and hallucinations are cause of serious distress for patients suffering from psychotic disorders, and how patients cope with them plays an important role in processes involved in decompensation and recovery, affecting the course of the illness. According to Lazarus and Folkman [1], coping is defined as a constantly changing process, where cognitive and behavioral efforts are used to manage demands appraised as exceeding the resources of a person. In the last 30 years, many studies have shown that patients develop coping strategies to deal with their psychopathological symptoms [2,3], and some of these proved to be effective $[4,5]$. Researchers have tried to understand the coping processes underlying the triggering and relapse of psychotic disorders [6], and developed approaches to treat chronic symptoms with cop-

\section{KARGER \\ Fax +41613061234 E-Mail karger@karger.ch} www.karger.com

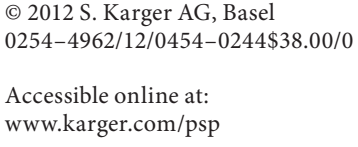

\footnotetext{
Sarah Rückl

Department of Psychiatry, University of Heidelberg

Vossstrasse 4

DE-69115 Heidelberg (Germany)

Tel. +496221 564 425, E-Mail sarah.rueckl@ med.uni-heidelberg.de
} 
ing-based therapies [7, 8]. Although a lot has been learned about the coping efforts of the patients, standardized coping inventories are rare [9]. Fallon and Talbot [10] were pioneers, describing how patients cope with chronic hallucinations. They assessed coping strategies through an exploratory interview, and classified them as changes in behavior, interpersonal contact, manipulation of physiological arousal, and cognitive coping strategies. After this initial approach, other researchers investigated coping strategies with hallucinations [11-13] and suggested similar classifications. The first researchers to explore coping with different symptoms of psychosis, including delusions, were Breier and Strauss [14]. According to them, coping is achieved by a three-step process: detection of unwanted behavior, its evaluation, and the employment of self-control strategies. Further studies attempted to assess coping with psychosis, using scales derived empirically, in an explorative way $[15,16]$, challenging the consistency of the results. Boschi et al. [17] used a reliable instrument, the Coping Response Inventory, developed by Moos [18], which was originally designed to evaluate coping with depression and alcohol abuse. Strategies used by patients to deal with any symptom present in schizophrenia were explored, but no attention was paid to the delusional experience. It is evident that most patients have to cope with a group of symptoms, and simply investigating coping with all symptoms present in psychosis may be a restricted perspective. A differentiated analysis of symptom patterns and coping strategies may be a more helpful approach [19]. Bak et al. [20] developed the Maastricht Assessment of Coping Strategies (MACS-I), a semi-structured interview, which assesses strategies used by patients to cope with 13 symptoms present in schizophrenia. Although it covers a considerable range of symptoms, it includes few coping strategies. Additional limitations of the existing interviews are that they are either too long for application in clinical routine or too complicated [21] for patients suffering from thought disorder or concentration deficits. Lazarus [22] suggested that the coping efforts employed for the different threats caused by a disorder vary with the adaptational significance and requirements of this threat, so when studying how a patient copes with an illness, it is necessary to specify the particular threat rather than focus attention on the overall disorder. To date, there are only a few manageable instruments for the assessment of coping strategies with delusional beliefs. The aim of this study was to develop a reliable and valid expert rating instrument for the assessment of coping with delusions.

\section{Methods}

Sample

Two hundred and twelve inpatients treated in the Department of Psychiatry of the University of Heidelberg, the Psychiatric Center Nordbaden in Wiesloch, and the Center of Mental Health in Stuttgart participated in the study. Inclusion criteria were current delusions within a schizophrenia spectrum disorder or affective disorder with psychotic symptoms. Exclusion criteria were severe clinical conditions, neurological diseases, addiction disorders, and poor German language ability. The participation was voluntary and written consent was obtained. Diagnoses were determined with the employment of a structured clinical interview [23]. The study protocol was approved by the local ethics committee, and was elaborated in accordance with the ethical standards laid down in the Declaration of Helsinki [24].

\section{Constructing the HCSD}

The initial item pool was created based on the existing instruments to assess coping strategies, theoretically based approaches, interviews with clinical psychiatrists and psychiatric patients. After this pilot phase, 33 strategies to cope with delusions were selected. To avoid difficulties and misunderstandings, a semi-structured interview was developed, and a middle level of abstraction for the coping items was chosen. Items were simple, straightforward and appropriate for the target population. Each strategy was rated on a 5-point Likert scale, from not at all to very much. Additionally, two items were constructed considering the transactional model after Lazarus and Folkman [1], and comprised the patient's suffering and control. These two items were also rated on a 5-point Likert scale, from not at all to very much. The last item of the HSCD assesses the three most helpful strategies to cope with delusions, considering the perspective of the patient. Five clinical psychologists were trained to apply the HCSD and identify the delusional belief, as well as the coping strategies used by the patients. To uncover the irrational belief, the patients were initially asked general questions, for example, why they were at the hospital. Another helpful approach was also to pose questions related to the most common delusion contents, as in the Structured Clinical Interview for DSM-IV Axis I Disorders [23]. In most of the cases, it was possible to identify the central delusional belief. Patients were then asked: (1) how much they suffered from their belief, and (2) how much control they had over it. As lists of previously selected strategies can have the disadvantage of concealing successfully used strategies, the patients were encouraged to name all strategies they used to handle their beliefs first. This assures the assessment of the patient's own experience with the symptom [5]. The answers were divided and allocated to different categories. For example: if a patient said he isolates himself and avoid other people, this answer was classified as 'social withdrawal'. We also inquired how intensively each strategy was used. Afterwards, patients were asked for the 33 predefined items of the HCSD. To determine how many coping strategies the patients used and how intensively, two coping indices were calculated. The Coping Repertoire Index (CRI) defines how many strategies the patients employ. Its range varies from 0 (no strategy used) to 33 (all strategies used). The Coping Intensity Index (CII) is the sum of all ratings from all strategies (coping intensity; $\mathrm{CI}$ ) divided by the number of strategies used by the patients (CRI). 


\section{Instruments}

Maastricht Assessment of Coping Strategies

The MACS-I [20] is a semi-structured interview, which assesses 13 core symptoms grouped in six categories: positive symptoms, negative symptoms, depressive symptoms, cognitive symptoms, hostility, and euphoria. The interviewer describes each symptom to the patient and asks if it was present in the last week. In the case of a positive answer, the patient indicates the degree of distress associated with the symptom, all strategies used to relief distress and the degree of control over the symptom. For each of the six groups of symptoms, the total number of the mentioned coping strategies is calculated. The degree of distress and control are rated on a 7-point ordinal scale. The authors reported inter-rater reliability by intraclass correlation coefficients (ICC) ranging from 0.90 to 0.97 . Factor analysis yielded a 5 -factor solution explaining $71 \%$ of variance. The component active problem-solving encloses distraction, problem-solving, and help-seeking. Prescribed medication, non-prescribed substances, and physical change are clustered together in the factor passive illness behavior. The third factor, active problem-avoiding, comprises shifted attention, socialization, task performance, and indulgence. Isolation, non-specific activities, and suppression are grouped together in the passive problemavoiding factor. The fifth factor is loaded by the item symptomatic behavior solely. For the convergent validity, only the items relevant for delusions were chosen: suspiciousness, delusion of reference, magical thinking and grandiosity.

\section{Statistical Analysis}

For psychometric evaluation, means, standard deviations (SD), facility values, and corrected item-total correlations were calculated. The facility value of an item is the frequency of subjects who react to the relevant item within the investigated characteristic [25]. The correlation between an item of the scale and the overall assessment score was obtained through the corrected item-total correlation. The measure of reliability was calculated through Cronbach's $\alpha$ coefficients [26]. Inter-rater reliability was analyzed by ICC [27]. All other associations were examined using Spearman rank-based correlations. Factorial validity was examined by principal component analysis with varimax rotation. Results were considered statistically significant if below $5 \%$ probability level. All analyses were performed with SAS version 9.12 for Windows (SAS Institute Inc., Cary, N.C., USA).

\section{Results}

\section{Sample Description}

The sample consisted of 212 currently deluded inpatients. One hundred and eighty-two (85.9\%) had a schizophrenia spectrum disorder, and from this subgroup, 143 (78.6\%) patients were diagnosed as schizophrenic, 29 (15.9\%) as schizoaffective, and $10(5.5 \%)$ patients had a delusional disorder. Thirty patients (14.1\%) were diagnosed with affective disorder with psychotic symptoms. From this subgroup, 28 (93.3\%) had unipolar depression and 2 patients $(6.7 \%)$ had bipolar disorder. The mean age of the $116(55 \%)$ female and $96(45 \%)$ male patients was
41.8 years $(\mathrm{SD}=12.8$, range $18-65)$ and the mean number of hospital admissions was $5.8(\mathrm{SD}=7.7)$. Most patients were single (53\%) and had 10 or less years of school (74\%). Forty-three percent of the patients were employed. All patients were taking psychotropic medication at the time of the assessment.

\section{Item Characteristics and Reliability}

Patients showed a moderate degree of suffering (mean $=2.6, \mathrm{SD}=1.3$ ) and had very low control over their belief (mean $=0.7, S D=1.0)$. More than half $(57 \%)$ of the patients could not influence their belief at all. The CRI showed that patients used on average $14.4(\mathrm{SD}=5.8)$ coping strategies, and the CII indicated that they used the strategies with moderate intensity (mean $=2.4, \mathrm{SD}=0.5$ ). Means, SD, average facility values, coping indices, and corrected item-total correlations are reported in table 1. The item facility values ranged from $\mathrm{p}=0.11$ (self-verbalization) to $\mathrm{p}=0.82$ (medical help), with an average facility value of 0.43 . Corrected item-total correlations showed values between 0.18 (alcohol and drug use) and 0.74 (positive emotions). The inter-rater reliability was calculated by comparing the results of two independent raters attending the interview in a sample of $87(41 \%)$ patients. ICC showed values between 0.66 (resigning) and 0.96 (psychotherapy).

\section{Factor Analysis of the HCSD Items}

The factorial validity of the HCSD (table 2) was examined by principal component analysis with single varimax rotation. The Kaiser-Guttmann criterion suggested a 9-factor solution, while the scree test pointed towards a 4 - or 5 -factor solution. A 5 -factor solution was chosen and explained a total variance of $46.6 \%$. The first factor, resource-oriented coping, was composed by positive re-evaluation, self-valorization, enjoyment, prosocial behavior, positive emotions, self-encouragement, humor, and searching for a meaning, and explained $13.5 \%$ of the variance. The second factor was named medical care and included the items medical help, psychotherapy, trusting the therapist, medication compliance, disease acceptance, and seeking information. It explained $12.3 \%$ of the variance. The third factor, distraction, consisted of the items alcohol and drug use, mental distraction, sensory distraction, distraction with specific activities, distraction with unspecific activities, acting out feelings, negative emotions, and body coping, and explained $7.2 \%$ of variance. The fourth factor, cognitive coping, was composed by the items minimization, dissimulation, ignoring, mental distraction, controlling 
Table 1. Item analysis, internal consistency, inter-rater reliability and coping indices of the HCSD $(\mathrm{n}=212)$

\begin{tabular}{|c|c|c|c|c|c|c|c|}
\hline & Mean & $\mathrm{SD}$ & Range & $\mathrm{P}$ & $\mathrm{r}_{\mathrm{it}}$ & $\begin{array}{l}\text { Cronbach's } \\
\alpha\end{array}$ & ICC \\
\hline Resource-oriented coping & 7.72 & 5.25 & $0-23$ & 0.28 & 0.56 & 0.83 & \\
\hline Positive re-evaluation & 0.53 & 1.07 & $0-04$ & 0.23 & 0.70 & 0.79 & 0.78 \\
\hline Self-valorization & 0.81 & 1.36 & $0-04$ & 0.32 & 0.55 & 0.82 & 0.93 \\
\hline Enjoyment & 0.76 & 1.17 & $0-04$ & 0.35 & 0.48 & 0.82 & 0.83 \\
\hline Prosocial behavior & 0.55 & 1.10 & $0-04$ & 0.23 & 0.58 & 0.81 & 0.88 \\
\hline Positive emotions & 0.48 & 1.02 & $0-04$ & 0.21 & 0.74 & 0.79 & 0.92 \\
\hline Self-encouragement & 0.87 & 1.18 & $0-04$ & 0.45 & 0.52 & 0.82 & 0.75 \\
\hline Humor & 0.45 & 0.94 & $0-04$ & 0.23 & 0.40 & 0.83 & 0.92 \\
\hline Searching for a meaning & 0.59 & 1.09 & $0-04$ & 0.28 & 0.51 & 0.82 & 0.78 \\
\hline Medical care & 5.04 & 6.09 & $0-27$ & 0.57 & 0.57 & 0.81 & \\
\hline Medical help & 2.00 & 1.30 & $0-04$ & 0.82 & 0.70 & 0.75 & 0.75 \\
\hline Psychotherapy & 0.68 & 1.20 & $0-04$ & 0.29 & 0.44 & 0.81 & 0.96 \\
\hline Trusting the therapist & 1.76 & 1.29 & $0-04$ & 0.79 & 0.68 & 0.75 & 0.87 \\
\hline Medication compliance & 1.98 & 1.37 & $0-04$ & 0.80 & 0.71 & 0.75 & 0.87 \\
\hline Disease acceptance & 0.87 & 1.16 & $0-04$ & 0.46 & 0.53 & 0.79 & 0.88 \\
\hline Seeking for information & 0.43 & 0.87 & $0-04$ & 0.25 & 0.38 & 0.82 & 0.84 \\
\hline Distraction & 5.93 & 4.16 & $0-19$ & 0.51 & 0.39 & 0.64 & \\
\hline Alcohol and drug use & 0.46 & 1.05 & $0-04$ & 0.19 & 0.18 & 0.68 & 0.94 \\
\hline Mental distraction & 1.07 & 1.18 & $0-04$ & 0.56 & 0.37 & 0.59 & 0.73 \\
\hline Sensory distraction & 1.59 & 1.47 & $0-04$ & 0.63 & 0.52 & 0.51 & 0.90 \\
\hline Distraction specific activities & 1.67 & 1.42 & $0-04$ & 0.66 & 0.47 & 0.54 & 0.91 \\
\hline Distraction unspecific activities & 1.14 & 1.27 & $0-04$ & 0.53 & 0.43 & 0.57 & 0.84 \\
\hline Cognitive coping & 2.94 & 3.16 & $0-15$ & 0.29 & 0.35 & 0.59 & \\
\hline Minimization & 0.42 & 0.87 & $0-04$ & 0.23 & 0.38 & 0.52 & 0.72 \\
\hline Dissimulation & 0.93 & 1.28 & $0-04$ & 0.40 & 0.52 & 0.44 & 0.74 \\
\hline Ignoring & 0.49 & 1.00 & $0-04$ & 0.26 & 0.25 & 0.59 & 0.83 \\
\hline Controlling feelings & 0.90 & 1.17 & $0-04$ & 0.47 & 0.39 & 0.52 & 0.81 \\
\hline Self-verbalization & 0.19 & 0.62 & $0-04$ & 0.11 & 0.21 & 0.61 & 0.80 \\
\hline Depressive coping & 4.76 & 3.24 & $0-12$ & 0.62 & 0.50 & 0.68 & \\
\hline Social withdrawal & 1.96 & 1.52 & $0-04$ & 0.69 & 0.47 & 0.62 & 0.82 \\
\hline Negative emotions & 1.84 & 1.36 & $0-04$ & 0.74 & 0.54 & 0.53 & 0.90 \\
\hline Resigning & 0.96 & 1.26 & $0-04$ & 0.45 & 0.48 & 0.61 & 0.66 \\
\hline Symptomatic behavior & 1.95 & 1.42 & $0-04$ & 0.75 & & & 0.90 \\
\hline CRI & 14.38 & 5.83 & $0-28$ & & & & \\
\hline $\mathrm{CI}$ & 33.03 & 15.09 & $0-82$ & & & & \\
\hline CII & 2.36 & 0.55 & $1-04$ & & & & \\
\hline
\end{tabular}

$\mathrm{P}=$ Average facility value; $\mathrm{r}_{\mathrm{it}}=$ average corrected item-total correlation .

feelings, acting out feelings, and self-verbalization, and explained $7.0 \%$ of variance. The fifth factor was called depressive coping and was loaded by the following items: minimization, social withdrawal, controlling feelings, negative emotions, and resigning. It explained $6.6 \%$ of variance. The item symptomatic behavior was considered as a separated factor. Once the aim of the factor analysis was to obtain interpretable dimensions with sufficient levels of internal consistency, the factor solution was slightly modified. In the distraction subscale, the items acting out feelings, negative emotions, and body coping were deleted. In the cognitive coping subscale, the items mental distraction and acting out feelings were excluded, and in the depressive coping subscale the items minimization and controlling feelings were removed. Levels of internal consistency were then calculated and were excellent for the factors resourceoriented coping $(\alpha=0.83)$ and medical care $(\alpha=0.81)$, while distraction $(\alpha=0.64)$, cognitive coping $(\alpha=0.59)$, and depressive coping $(\alpha=0.68)$ showed moderate val- 
Table 2. Principal component analysis with varimax rotation of the HCSD $(n=212)$

\begin{tabular}{|c|c|c|c|c|c|c|}
\hline & Factor 1 & Factor 2 & Factor 3 & Factor 4 & Factor 5 & $h^{2}$ \\
\hline Medical help & 0.07 & $0.83^{*}$ & 0.07 & 0.01 & 0.02 & 0.70 \\
\hline Psychotherapy & 0.20 & $0.55^{*}$ & -0.05 & 0.05 & 0.04 & 0.34 \\
\hline Trusting the therapist & 0.09 & $0.80^{*}$ & 0.09 & 0.05 & 0.10 & 0.67 \\
\hline Medication compliance & 0.01 & $0.79^{*}$ & 0.04 & 0.08 & 0.19 & 0.67 \\
\hline Alcohol and drug use & 0.03 & -0.33 & $0.51^{*}$ & -0.07 & -0.01 & 0.37 \\
\hline Disease acceptance & 0.17 & $0.66^{*}$ & 0.02 & 0.06 & 0.08 & 0.47 \\
\hline Seeking for information & 0.24 & $0.42^{*}$ & 0.16 & 0.19 & -0.13 & 0.31 \\
\hline Positive re-evaluation & $0.81^{*}$ & 0.08 & 0.04 & -0.09 & -0.06 & 0.67 \\
\hline Self-valorization & $0.70^{*}$ & -0.20 & -0.02 & -0.14 & -0.18 & 0.57 \\
\hline Relativization & 0.33 & 0.23 & 0.00 & 0.10 & 0.12 & 0.18 \\
\hline Minimization & 0.36 & -0.14 & 0.00 & $0.43^{*}$ & $0.45^{*}$ & 0.54 \\
\hline Dissimulation & 0.34 & 0.07 & 0.04 & $0.51^{*}$ & 0.29 & 0.46 \\
\hline Ignoring & 0.05 & 0.00 & 0.10 & $0.49^{*}$ & 0.02 & 0.25 \\
\hline Mental distraction & 0.07 & 0.21 & $0.42^{*}$ & $0.42^{* *}$ & 0.10 & 0.40 \\
\hline Sensory distraction & 0.03 & 0.04 & $0.58^{*}$ & 0.38 & 0.10 & 0.49 \\
\hline Distraction with specific activities & -0.04 & 0.23 & $0.60^{*}$ & 0.29 & -0.02 & 0.49 \\
\hline Distraction with unspecific activities & 0.03 & 0.05 & $0.63^{*}$ & 0.24 & 0.07 & 0.46 \\
\hline Social assistance & 0.13 & 0.36 & 0.24 & 0.10 & -0.37 & 0.35 \\
\hline Social withdrawal & -0.03 & 0.08 & 0.14 & -0.03 & $0.79 *$ & 0.65 \\
\hline Enjoyment & $0.60^{*}$ & 0.12 & 0.03 & 0.13 & 0.03 & 0.39 \\
\hline Prosocial behavior & $0.66^{*}$ & 0.26 & -0.07 & 0.04 & 0.03 & 0.50 \\
\hline Controlling feelings & 0.14 & 0.32 & 0.02 & $0.47^{*}$ & $0.40^{*}$ & 0.50 \\
\hline Acting out feelings & 0.27 & 0.07 & $0.48^{*}$ & $-0.45^{*}$ & 0.08 & 0.52 \\
\hline Negative emotions & -0.19 & 0.36 & $0.41^{*}$ & -0.11 & $0.55^{*}$ & 0.65 \\
\hline Positive emotions & $0.83^{*}$ & -0.01 & 0.03 & -0.20 & -0.12 & 0.75 \\
\hline Self-encouragement & $0.58^{*}$ & 0.30 & 0.05 & 0.27 & 0.10 & 0.50 \\
\hline Humor & $0.49^{*}$ & 0.02 & 0.11 & 0.18 & -0.07 & 0.29 \\
\hline Religiosity & 0.28 & 0.21 & -0.05 & 0.08 & 0.16 & 0.15 \\
\hline Searching for a meaning & $0.59^{*}$ & 0.20 & -0.06 & 0.07 & -0.12 & 0.40 \\
\hline Resigning & -0.18 & 0.14 & 0.09 & 0.13 & $0.60^{*}$ & 0.43 \\
\hline Body coping & -0.07 & 0.03 & $0.45^{*}$ & -0.20 & 0.07 & 0.20 \\
\hline Self-verbalization & -0.06 & 0.24 & 0.07 & $0.57^{*}$ & -0.11 & 0.40 \\
\hline Percentage of variance & $13.5 \%$ & $12.3 \%$ & $7.2 \%$ & $7.0 \%$ & $6.6 \%$ & \\
\hline
\end{tabular}

ues. Spearman correlations between the HCSD coping scales showed values between 0.13 and 0.35 .

\section{Correlations between Coping Subscales and Coping Indices}

Significant positive correlations were demonstrated between the CRI and resource-oriented coping $(\mathrm{r}=0.53$, $\mathrm{p}<0.001)$, medical care $(\mathrm{r}=0.52, \mathrm{p}<0.001)$, distraction $(\mathrm{r}=0.58, \mathrm{p}<0.001)$, cognitive coping $(\mathrm{r}=0.54, \mathrm{p}<0.001)$, and depressive coping $(\mathrm{r}=0.31, \mathrm{p}<0.001)$. No significant correlations with symptomatic behavior were found $(r=$ $0.06, \mathrm{p}=0.33$ ). The CRI also correlated significantly and negatively with the CII $(r=-0.20, p<0.01)$, but positive- ly with the CI $(\mathrm{r}=0.87, \mathrm{p}<0.001)$. The CII showed significant and positive correlations with resource-oriented coping $(\mathrm{r}=0.14, \mathrm{p}<0.05)$ and the $\mathrm{CI}(\mathrm{r}=0.21, \mathrm{p}<0.01)$. The CI presented significant positive correlations with resource-oriented $(r=0.65, p<0.001)$, medical care $(r=$ $0.53, \mathrm{p}<0.001)$, distraction $(\mathrm{r}=0.60, \mathrm{p}<0.001)$, cognitive coping $(\mathrm{r}=0.58, \mathrm{p}<0.001)$, and depressive coping $(\mathrm{r}=$ $0.39, \mathrm{p}<0.001)$. No significant correlations were found with symptomatic behavior $(\mathrm{r}=0.09, \mathrm{p}=0.17)$.

\section{Convergent Validity}

For validation, the HCSD were correlated with the MACS-I (table 3). Almost all subscales from the HCSD 
Table 3. Spearman correlations between the MACS-I and the HCSD subscales and indexes $(\mathrm{n}=34)$

\begin{tabular}{|c|c|c|c|c|c|c|}
\hline & $\begin{array}{l}\text { Passive } \\
\text { illness } \\
\text { behavior }\end{array}$ & $\begin{array}{l}\text { Active } \\
\text { problem } \\
\text { solving }\end{array}$ & $\begin{array}{l}\text { Passive } \\
\text { problem } \\
\text { avoiding }\end{array}$ & $\begin{array}{l}\text { Active } \\
\text { problem } \\
\text { avoiding }\end{array}$ & $\begin{array}{l}\text { Symptomatic } \\
\text { behavior }\end{array}$ & Total \\
\hline Resource-oriented & $0.41^{*}$ & $0.59^{* *}$ & $0.39^{*}$ & 0.12 & -0.32 & $0.37^{*}$ \\
\hline Medical care & -0.03 & 0.09 & -0.07 & 0.18 & -0.20 & 0.04 \\
\hline Distraction & $0.36^{*}$ & $0.62^{* * *}$ & $0.65^{* * *}$ & $0.46^{* *}$ & -0.11 & $0.67^{* * *}$ \\
\hline Cognitive coping & 0.31 & $0.35^{*}$ & $0.67^{* * *}$ & 0.22 & $-0.36^{*}$ & $0.42^{*}$ \\
\hline Depressive coping & 0.15 & 0.27 & $0.41^{*}$ & -0.02 & -0.05 & 0.21 \\
\hline Symptomatic behavior & -0.20 & -0.27 & $-0.39^{*}$ & -0.04 & $0.47^{* *}$ & -0.16 \\
\hline CRI & 0.33 & $0.54^{* *}$ & $0.58^{* *}$ & $0.35^{*}$ & -0.14 & $0.56^{* *}$ \\
\hline $\mathrm{CI}$ & $0.43^{* *}$ & $0.57^{* *}$ & $0.66^{* * *}$ & $0.36^{*}$ & -0.32 & $0.60^{* * *}$ \\
\hline CII & -0.15 & -0.18 & -0.11 & -0.29 & -0.15 & -0.20 \\
\hline
\end{tabular}

correlated significantly with the MACS-I domains. The item symptomatic behavior from the HCSD showed significant correlations with symptomatic behavior from the MACS-I. The coping indices CRI and CI correlated significantly with the MACS-I domains, while the CII did not.

\section{Discussion}

The aim of this study was to develop and evaluate the psychometric properties of an expert rating instrument to assess coping with delusions. The identification of how patients cope with this particular symptom is of major interest in research and clinical practice. Psychiatrists are seldom aware of the coping strategies used by their patients [2], although how patients cope with their symptoms plays an important role in recovery and chronification [28].

Even though more than half of the patients reported not being able to control their belief, the use of about 14 coping strategies was reported. These findings confirm the results of previous studies that the majority of patients use coping strategies, but the degree of success varies $[4,5,10,14,15,21]$. The 3 most frequently used coping strategies were medical help (82\%), medication compliance $(80 \%)$, and trusting the therapist $(79 \%)$; while the strategies that the patients judged as the 3 most helpful ones were medical help, distraction with specific activities, and social interaction. These results show a discrepancy between the most used coping strategies and the strategies rated as the most helpful. Carter et al. [12] stud- ied a group of patients with auditory hallucinations, and also demonstrated that the coping strategies rated as the most frequently used were not the most effective. The fact that the most frequently used strategies belonged to the medical care subscale suggests that the patients were aware of need for treatment. The recognition of need for treatment is related to insight, but it is not direct evidence of it. Insight is a multidimensional construct, which involves the awareness of having a disorder, attributing symptoms to a disorder, and acknowledging the need for treatment [29]. Many patients require treatment despite not recognizing being ill [30]. In this sample, $75 \%$ of the patients also showed symptomatic behavior, defined as going along with and indulging in the context of psychotic symptoms [16], suggesting a lack of awareness of having a disorder and attributing the symptom delusion to it.

The inter-rater reliability of the HCSD was excellent. The majority of the HCSD items showed good item characteristics and psychometric properties. The item facility value represents the number of patients scoring on an item. It showed that $82 \%$ of the patients used medical help as coping strategy, while self-verbalization was only mentioned by $11 \%$. Most of the HCSD items showed moderate corrected item-total correlations.

The factorial validity of the HCSD was demonstrated by a 5 -factor solution as the best representation of the data structure: resource-oriented coping, medical care, distraction, cognitive coping, and depressive coping. Due to its particularity, it was decided to include the item symptomatic behavior as a separated factor. Is symptomatic behavior a coping strategy? Evidence has demonstrated that symptomatic and non-symptomatic coping 
are negatively correlated, suggesting that this kind of coping may be more an autonomous response than properly coping [31]. Bak et al. [20] also found a 5-factor structure in the MACS-I, however, with different coping dimensions. Factor solutions may differ depending on the coping strategies included in the scales, and no consensus has so far been achieved. As pointed by Ristner et al. [32], one of the major problems of coping research is the lack of defined patters of coping behavior, their prevalence, and attribution among schizophrenic patients.

The psychometric evaluation of the HCSD subscales showed good item statistics and internal consistency. The HCSD subscales showed low to moderate correlations with each other. The CRI showed significant correlations with almost all coping subscales from the HCSD, with the exception of symptomatic behavior. This indicates that patients who used resource-oriented coping, medical care, distraction, cognitive coping, and depressive coping used more strategies compared to patients with symptomatic behavior. Lardinois et al. [31] suggested that patients, who use symptomatic coping, have lower levels of coping in daily life and tend to use only symptomatic coping, although it has been considered an ineffective strategy. The association of multiple strategy use and strategy effectiveness has already been reported $[2,4,10,18]$. The correlations of the CRI with the CII were negative, suggesting that patients with a larger coping repertoire cope less intensively, while patients with a narrowed coping repertoire use their strategies more intensively. The CII correlated significantly with resource-oriented coping and showed no other correlations, leading to the conclusion that patients who used resource-oriented coping to deal with their delusion, used the strategies more intensively.

Significant correlations between the total score from MACS-I with the CRI and CI from the HCSD could be shown. The MACS-I measures the total number of strategies used by patients, as well as the total intensity of the ratings from patients, but it does not assess the intensity of the used strategies as defined in the CII. Since the CII correlates with the CRI and indicates the intensity of the used strategies, it is a more differentiated parameter. The results showed the good convergent validity of the HSCD and the MACS-I total scores. No domain from the MACSI correlated with the medical care subscale from HCSD. This domain is measured in the MACS-I through two items, help seeking and prescribed medication, which loaded in two separated factors: active problem-solving and passive illness behavior, respectively. Depressive coping showed significant correlations with passive problem avoiding from the MACS-I. Isolation is a similar item in both subscales. Symptomatic behavior from both scales correlated significantly. Because of similar items, the other 3 subscales of the HCSD - resource-oriented coping, distraction, and cognitive coping - showed significant correlations with almost all factors from the MACS-I. Nevertheless, the factors do not measure the same set of coping strategies.

In conclusion, the results showed that it is possible to reliably assess coping with delusions. The HSCD proved to be a manageable and economic expert rating scale to use in research and clinical practice. Good reliability and convergent validity in the assessment of coping strategies with delusions in a sample of schizophrenic and affective patients were shown. Factor analysis yielded five interpretable and consistent factors: resource-oriented coping, medical care, distraction, cognitive coping, and depressive coping. Symptomatic coping was considered apart. Coping indices, such as the CRI and the CII, could be calculated.

A limitation of the present study is that only inpatients were assessed [33-35]. A broader deficit in adaptive coping in inpatients can be expected compared to community-treated patients [28]. Future studies should include a more heterogeneous sample, including outpatients. The analysis was based on cross-sectional data. Longitudinal studies to evaluate coping changes over time could be useful to appraise clinical outcomes and treatment trials.

\footnotetext{
References $\quad 1$ Lazarus RS, Folkman S: Stress, appraisal, and coping. Springer, New York, 1984.

2 Dittmann J, Schüttler R: Disease consciousness and coping strategies of patients with schizophrenic psychosis. Acta Psychiatr Scand 1990;82:318-322.

-3 Peter WH, Lee F, Lieh-Mak KK, Spinks JA: Coping strategies of schizophrenic patients and their relationship to outcome. Brit J Psychiat 1993;163:177-182.

4 Tarrier N: An investigation of residual psychotic symptoms in discharged schizophrenic patients. Brit J Clin Psychol 1987;26: 141-143.

5 McNally SE: Natural cognitive coping strategies in schizophrenia. Brit J Med Psychol 1997;70:159-167.

-6 Thurm I, Haefner H: Perceived vulnerability, relapse risk and coping in schizophrenia. Europ Arch Psy Clin N 1987;237:46-53.

7 Tarrier N, Harwood S, Yusopoff L, Becket R, Baker A: Coping Strategy Enhancement (CSE): a method of treating residual schizophrenic symptoms. Behav Psychother 1990; $18: 643-662$.
} 
$\checkmark 8$ Wiersma D, Jenner JA, van de Willige G, Spakman M, Nienhuis FJ: Cognitive behavior therapy with coping training for persistent auditory hallucinations in schizophrenia: a naturalistic follow-up study of the durability of effects. Acta Psychiatr Scand 2001; 103:393-399.

-9 Meyer B: Coping with severe mental illness: relation of the brief COPE, functioning, and well-being. J Psychopathol Behav 2001;23: 265-277.

10 Fallon IRH, Talbot RE: Persistent auditory hallucinations: coping mechanisms and implications for management. Psychol Med 1981;11:329-339.

-11 O’Sullivan K: Dimensions of coping with auditory hallucinations. J Ment Health 1994;3: 351-361.

-12 Carter D, McKinnon A, Copolov D: Patients' strategies for coping with auditory hallucinations. J Nerv Ment Dis 1996;184:159-164.

13 Farhall J, Greenwood KM, Jackson HJ: Coping with hallucinated voices in schizophrenia: a review of self-initiated strategies and therapeutic interventions. Clin Psychol Rev 2007;27:476-493.

14 Breier A, Strauss JS: Self-control in psychotic disorders. Arch Gen Psychiatry 1993;40: 1141-1145.

15 Cohen CI, Berk LA: Personal coping styles of schizophrenic outpatients. Hosp Community Psych 1985;36:407-410.

16 Carr V: Patients techniques for coping with schizophrenia: an exploratory study. $\mathrm{Br} \mathrm{J}$ Med Psychol 1988;61:339-352.

- 17 Boschi S, Adams RE, Bromet EJ, Lavelle JE, Everett E, Galambos N: Coping with psychotic symptoms in the early phases of schizophrenia. Am J Orthopsychiatry 2000; 70:242-252.
18 Moos RH: Coping: Konzepte und Messverfahren. Z Psychosom Med Psyc 1988;34:207225.

19 Wiedl KH, Schöttner B: Coping with symptoms related to schizophrenia. Schizophr Bull 1991;17:525-538.

20 Bak M, van der Spil F, Gunther N, Radstake S, Delespaul P, van Os J: Maastricht Assessment of Coping Strategies (MACS-I): a brief instrument to assess coping with psychotic symptoms. Acta Psychiatr Scand 2001;103. 453-459.

21 Wiedl KH: Assessment of coping with schizophrenia: stressors, appraisals, and coping. Brit J Psychiatr 1992;18:114-122.

22 Lazarus RS: Coping theory and research past, present, and future. Psychosom Med 1993;55:234-247.

23 Wittchen HU, Wunderlich U, Gruschwitz S Zaudig M: Strukturiertes Klinisches Interview fuer DSM-IV, Achse-I (SKID). Beltz, Göttingen, 1997.

24 World Medical Organization: Declaration of Helsinki. Brit Med J 1996;313:1448-1449.

25 Kline P: A handbook of test construction: introduction to psychometric design. London, Methuen and Company, 1986.

26 Cronbach LJ: Coefficient alpha and the internal structure of tests. Psychometrika 1951; 16:297-333.

27 Shrout PE, Fleiss JL: Intraclass correlations uses in assessing rater reliability. Psychol Bull 1979;86:420-428.

28 Ristner MS, Ratner Y: The long-term changes in coping strategies in schizophrenia. J Ner Ment Dis 2006;194:261-267.
29 David AS: Insight and psychosis. Brit J Psychiatr 1990;156:798-808.

30 McEvoy JP, Aland J, Wilson WH, Guy W, Hawkins L: Measuring chronic schizophrenic patients' attitudes toward their illness and treatment. Hosp and Community Psych 1981;32:856-858.

31 Lardinois M, Myin-Germeys I, Bak M, Mengelers R, van Os J, Delespaul PAEG: The dynamics of symptomatic and non-symptomatic coping with psychotic symptoms in the flow of daily life. Acta Psychiatr Scand 2007;116:71-75.

-32 Ristner MS, Gibel A, Ponizovsky AM, Shinkarenko E, Ratner Y, Kurs R: Coping patterns as a valid representation of the diversity of coping responses in schizophrenia patients. Psychiat Res 2006;144:139-152.

33 Büche L, Gentner NC, Kaiser S, von Bock A, Grupe S, Joest K, Barthel A, Vedder H, Mundt C, Kronmüller KT: Dimensions of delusional experience scale: a psychometric evaluation of a German version. Psychopathology 2010;43:189-196.

34 Gentner NC, Büche L, von Bock A, Rückl S, Marx J, Kaiser S, Barthel A, Vedder H, Mundt C, Kronmüller KT: Psychometric evaluation of the characteristics of delusions rating scale as an expert rating scale. Psychopathology 2010;43:373-380.

35 Kronmüller KT, von Bock A, Grupe S, Büche L, Gentner NC, Rückl S, Marx J, Joest K, Kaiser S, Vedder H, Mundt C: Psychometric evaluation of the Psychotic Symptom Rating Scale (PSYRATS). Compr Psychiatry 2011; 52:102-108. 